\title{
PENGGUNAAN MEDIA SOSIAL WHATSAPP PADA PEMBELAJARAN AGAMA HINDU UNTUK DI MASA PANDEMI
}

\author{
Ni Putu Sri Agustini \\ Guru SD N 2 Mengwitani, Bali, Indonesia \\ Email: sriagustiniagustus1985@gmail.com
}

\begin{abstract}
ABSTRAK
Pembelajaran Daring dengan Whatsapp Group di kelas IV SD No.2 Mengwitani, berupa pemecahan masalah, mengkreasikan konten, menciptakan suatu karya, melakukan hobi, menanggapi dan menjawab siswa dan guru serta hal-hal yang mengasah keterampilan siswa. Dampak dari kegiatan tersebut untuk kelas IV SD No. 2 Mengwitani meliputi perilaku kreatif antara lain siswa menyatakan ide atau tanggapan yang dimilikinya kepada siswa lain, siswa bersikap terbuka dengan mendengarkan pendapat dari orang lain, dan siswa menghasilkan ide atau karya yang baru serta melakukan percobaan yang baru. Siswa juga mencoba memanfaatkan media sosial WhatsApp untuk saling mengingatkan kepada sesama teman agar mengerjakan tugas yang diberikan oleh Guru. Ada pula yang saling menyemangati satu sama lain melalui status WhatsApp dalam hal belajar agar motivasi untuk belajar terbentuk. Fitur WhatsApp juga dimanfaatkan oleh para pendidik, seperti fitur dokumen. Pendidik menggunakan fitur tersebut dengan mengirimkan bacaan yang bermanfaat atau materi pelajaran yang akan dipelajari maupun yang sudah dipelajari di dalam grup WhatsApp untuk kemudian dibaca dan dipelajari oleh siswa. WhatsApp dapat menjadi media pembelajaran yang baik serta untuk memotivasi belajar untuk para penggunanya, terutama untuk para siswa.
\end{abstract}

Kata kunci: WhatsApp, Pembelajaran Daring.

\begin{abstract}
Online Learning with Whatsapp Group in grade IV SD No.2 Mengwitani, in the form of problem solving, creating content, creating works, doing hobbies, responding to and answering students and teachers as well as things that hone students' skills. The impact of these activities for grade IV SD No. 2 Mengwitani includes creative behavior, including students expressing their ideas or responses to other students, students being open by listening to the opinions of others, and students producing new ideas or works and doing new experiments. Students also try to use WhatsApp social media to remind each other to do the tasks given by the teacher. There are also those who encourage each other through WhatsApp status in terms of learning so that motivation to learn is formed. Educators also use WhatsApp features, such as the document feature. Educators use this feature by sending useful reading or subject matter that will be studied or learned in the WhatsApp group for later reading and learning by students. WhatsApp can be a good learning medium and to motivate learning for its users, especially for students.
\end{abstract}

Keywords: WhatsApp, Online Learning. 


\section{PENDAHULUAN}

Perkembangan teknologi di zaman yang modern seperti sekarang ini menjadikan kita terbiasa menggunakan teknologi yang serba mudah dan cepat misalnya pada dunia informasi dan komunikasi. Pada masa sekarang ini media terpenting dan memiliki jaringan paling luas adalah internet. Media internet ini sangat berkembang pesat dan selalu memberikan inovasi kepada penggunanya sesuai dengan kebutuhan sekarang. Hampir semua media dan kebutuhan masyarakat dikoneksikan melalui internet, sehingga internet dapat memberikan banyak pengaruh terhadap kebutuhan manusia dari segala bidang.

Teknologi yang berkembang di bidang informasi sangat dimanfaatkan dalam dunia pendidikan untuk mencari sumber referensi belajar dalam bentuk online. Banyak situs web yang menyediakan materi pelajaran untuk kemudian dibaca dan dipelajari melalui online. Selain situs web, perkembangan pada dunia komunikasi juga sudah sangat berkembang, khususnya media sosial. Media sosial banyak dimanfaatkan oleh siswa untuk mencari teman baru, chatting, atau membuat grup untuk berdiskusi masalah pelajaran. Adanya media sosial membuat orang mudah berinteraksi dengan teman, saudara serta orang lain secara jarak jauh. Teknologi dapat membantu dan mempermudah manusia dalam mengerjakan pekerjaannya sehingga dapat selesai dengan lebih efektif dan efisien.

Perkembangan teknologi di era modern sudah sangat mudah untuk diakses oleh siapapun, kapanpun dan di manapun. Contoh seperti sekarang ini hampir semua alat komunikasi seperti smartphone menyediakan aplikasi yang memudahkan penggunanya untuk mengakses internet. Melalui internet, pengguna dapat mengkases media sosial yang diinginkan, seperti facebook, twitter, instagram, gmail, whatsApp, dan lain sebagainya. Sekarang yang sedang marak dipakai adalah media sosial WhatsApp. WhatsApp merupakan aplikasi pesan instan untuk smartphone. Jika dilihat dari fungsinya WhatsApp hampir sama dengan aplikasi SMS yang biasa digunakan pada ponsel lama, tetapi WhatsApp tidak menggunakan pulsa, melainkan data internet. WhatsApp juga dapat diaplikasikan dengan cara mengirim gambar, video, berdiskusi, mengirim dokumen berupa word dan masih banyak lagi.

Guru mencoba memanfaatkan media internet sebagai media mencari informasi seputar pembelajaran, misalnya dengan menugaskan siswa dengan mengirim tugas melalui email ataupun mencari bahan informasi seputar pelajaran di internet. Guru juga memanfaatkan media sosial seperti grup whatsApp untuk berdiskusi masalah pelajaran yang memang belum dipahami pada saat pandemi, bertanya seputar tugas, memotivasi siswa untuk semangat belajar ataupun memberikan informasi berupa pengumuman melalui grup whatsApp kelas.

Penggunaan aplikasi WhatsApp membuat siswa menjadi lebih ekspresif dengan membuat status, upload foto dengan caption yang tekadang aneh bahkan juga memotivasi dan berbagi video. Siswa juga mencoba memanfaatkan media sosial WhatsApp untuk saling mengingatkan kepada sesama teman agar mengerjakan tugas yang diberikan oleh Guru. Ada pula yang saling menyemangati satu sama lain melalui status WhatsApp dalam hal belajar agar motivasi untuk belajar terbentuk. Fitur WhatsApp juga dimanfaatkan oleh para pendidik, seperti fitur dokumen. Pendidik menggunakan fitur tersebut dengan mengirimkan bacaan yang bermanfaat atau materi pelajaran yang akan dipelajari maupun yang sudah dipelajari di dalam grup WhatsApp untuk kemudian dibaca dan dipelajari oleh siswa. WhatsApp dapat menjadi media pembelajaran yang baik serta untuk memotivasi belajar untuk para penggunanya, terutama untuk para siswa.

\section{METODE PENELITIAN}

Sebuah karya ilmiah tidak bisa lepas dari penggunaan metode. Metode penelitian itu merupakan cara ilmiah agar bisa memperoleh dan bisa mengumpulkan data-data dengan fungsi dan tujuan tertentu. Ada beberapa hal yang perlu untuk di ketahui dan di pahami 
mengenai pengertian metode penelitian yakni cara ilmiah, data-dara, fungsi dan juga tujuannya. Cara ilmiah maksudnya, kegiatan penelitian pastinya di dasarkan oleh ketentuan, syarat serta ciri- ciri keilmiahan yakni empiris, rasional dan juga sistematis. Empiris adalah penelitian yang mana di lakukan dengan cara mengamati oleh indera manusia.. Rasional adalah penelitian yang mana di lakukan dengan memakai cara yang masuk akan dan bisa sesuai dengan nalar manusia. Sistematis sendiri memiliki arti sebagai proses penelitian yang mana dilaksanakan dengan langkah-langkah khusus yang memiliki sifat logis.Adapun metode yang digunakan dalam karya ilmiah ini adalah metode penelitian kualitatif.

Metode Penelitian Kualitatif adalah metode yang lebih menekankan pada aspek pemahaman secara mendalam terhadap suatu masalah daripada melihat permasalahan untuk penelitian generalisasi. Metode penelitian ini menggunakan teknik analisis mendalam, yaitu mengkaji masalah secara kasus perkasus karena metodologi kulitatif yakin bahwa sifat suatu masalah satu akan berbeda dengan sifat dari masalah lainnya.

Metode penelitian kualitatif sering disebut metode penelitian naturalistik karena penelitiannya dilakukan pada kondisi yang alamiah (natural setting); disebut juga sebagai metode etnographi, karena pada awalnya metode ini lebih banyak digunakan untuk penelitian bidang antropologi budaya; disebut sebagai metode kualitatif, karena data yang terkumpul dan analisisnya lebih bersifat kualitatif.

\section{HASIL DAN PEMBAHASAN}

Pembelajaran daring dengan sosial media merupakan pilihan sebagai pembelajaran inovatif pada masa pandemi ini. Materi yang diajarkan dengan sosial media tidak hanya sebagai bahan pembelajaran tetapi juga sekaligus dapat diarsipkan sebagai portofolio untuk kemajuan belajar siswa ( Xue \& Churcill, 2020 :21). Pembelajaran ini juga mampu menarik minat siswa sehingga siswa lebih bersemangat untuk belajar. Pembentukan minat siswa merupakan bekal yang penting untuk kesuksesan pembelajaran. Sosial media WhatsApp Group menjadi salah satu pilihan di SD No.2 Mengwitani. Pembelajaran dengan menggunakan WhatsApp Group dipilih oleh pembelajaran kelas IV SD No.2 Mengwitani dikarenakan mudah pengoperasiannya, pembelajaran menjadi aktif, bisa dilakukan dimanapun dan kapanpun, juga bisa mendukung pembelajaran individu maupun kelompok. Sesuai dengan Cetinkaya (2020: 69) bahwa pembelajaran dengan whatsApp memiliki mavfaat pada motivasi siswa dan relevan dengan semua konten.

Pembelajaran ini dilakukan dengan memanfaatkan fitur-fitur yang tersedia. Adapun langkah-langkah pembelajaran dengan WhatsApp Group di SD No. 2 Mengwitani meliputi Siswa diberikan pembelajaran agama Hindu melalui gambar. Materi tersebut telah disesuaikan dengan pemetaan kompetensi dasar. Siswa melakukan presensi dengan cara mengirimkan pesan pribadi kepada guru. Tujuannya untuk mengecek kehadiran siswa dalam pembelajaran daring. Selanjutnya guru memberikan pertanyaan-pertanyaan yang harus dijawab pada saat itu juga sebagai kegiatan apersepsi. Siswa menerima materi dari guru diantaranya berupa video rekaman guru, video youtube, artikel, komik strip, poster, dan gambar. Pembelajaran dengan media pembelajaran dan kreatif sesuai Utaminingsih, Agustini, Aniq (2019: 65) menyebabkan pembelajaran lebih menarik, tujuan pembelajaran tercapai lebih mudah karena materi lebih jelas dan mudah dipahami siswa. Setelah siswa mengakses materi tersebut, siswa diberikan tugas yang dilakukan mandiri atau kolaborasi dengan keluarga. Tugas tersebut bersifat fleksibel berupa pemecahan masalah, mengkreasikan konten, menciptakan suatu karya, melakukan hobi, dan halhal yang mengasah keterampilan siswa dengan batasan waktu yang relatif luas sesuai dengan materi pelajaran agama Hindu di kelas IV.

Fleksibelitas dalam pembelajaran daring berupa siswa berhak memilih waktu dan tempat untuk mengakses pembelajaran yang inovatif. Siswa melaporkan tugas individu maupun kolaborasinya dengan mengirimkan gambar, video, melakukan panggilan suara, atau panggilan video pribadi maupun kelompok kepada guru atau pada obrolan kelompok. Beberapa siswa menanggapi laporan hasil dari siswa lain. WhatsApp juga bisa meneruskan pesan, sehingga 
memudahkan apabila siswa ingin berbagi dengan teman yang lain (Sahidillah \& Miftahurrisqi, 2019:54). Selanjutnya Guru mengirimkan video penguatan pembelajaran. Evaluasi pembelajaran dilakukan dengan guru mengirimkan pesan pada WhatsApp Group, atau google form. Sesuai dengan Salam (2020:209) aktivitas belajar melalui WhatsApp yang terjadi meliputi kehadiran siswa, pembelajaran tutor, bertanya, memberikan tanggapan atau jawaban, serta menyelesaikan tugas. Pemanfaatan WhatsApp bisa dilakukan untuk pengetahuan, sikap, maupun keterampilan siswa. WhatsApp merupakan media yang digunakan pada pembelajaran agama Hindu di SD No.2 Mengwitani. Karena memudahkan pengoprasian bagi siswa maupun guru.

Belajar dari rumah bagi siswa dan mengajar/bekerja dari rumah bagi guru untuk semua jenjang pendidikan. Belajar dari rumah atau secara konseptual adalah pembelajaran jarak jauh ini termasuk baru untuk jenjang SMP, sehingga berimplikasi pada proses pelaksanaannya.

\section{Strategi Pembelajaran Daring di SD No 2 Mengwitani:}

Dalam proses pembelajaran daring di SD No.2 Mengwitani para guru tidak sendiri lagi mengelola pembelajaran seperti di sekolah, demikian juga orang tua tidak lagi dapat menyerahkan seluruh aktivitas belajar anak kepada guru, namun orang tua dan guru bekerja sama untuk mendampingi siswa dalam kegiatan belajarnya. Perubahan ini dirasakan oleh siswa, guru dan juga orangtua, sehingga dibutuhkan strategi untuk efektivitas komunikasinya.

Interaksi guru dan orang tua dalam proses kegiatan belajar anak membutuhkan strategi yang dapat menyesuaikan karakteristik siswa, guru, orang tua yang memenuhi kriteria pembelajaran jarak jauh.

Untuk membantu guru dan orang tua dalam mengoptimalkan tumbuh kembang anak melalui kegiatan belajar di rumah, dibutuhkan suatu pedoman yang dapat memberikan petunjuk bagi guru dan orang tua. Dengan demikian, pedoman ini disusun agar guru dan orang tua dapat bekerja sama secara efektif dalam memberikan kegiatan stimulasi perkembangan anak selama belajar di rumah.

\section{Dampak Pembelajaran Daring dengan Whatssapp Group pada Perilaku Kreatif Siswa Kelas IV SD No.2 Mengwitani.}

Beberapa fitur whatsapp group yang telah dimanfaatkan yaitu fasilitas obrolan grup, pengirim dokumen, video, gambar, panggilan suara maupun panggilan video. Sesuai dengan Prajana (2017) konten whatsapp group yang bisa digunakan meliputi chat group untuk intregasi antara gurudan siswa, Fasilitas share document digunakan untuk membantu kelompok belajar mengirim dokumen dalam bentuk file, Kamera digunakan untuk membagi beberapa kegiatan untuk membutuhkan gambar yang diambil pada sebuah kegiatan, dan Audio digunakan untuk membagikan berupa suara.

Pembelajaran dengan menggunakan whatsapp tengah populer selama masa pandemi. Kemudahan pengoperasian menjadi alasan memilih media tersebut. Penggunaan whatsapp dilakukan mulai kegiatan pendahuluan hingga kegiatan penutup. Kegiatan tersebut dilakukan dengan pembelajaran yang berpusat pada siswa. Meskipun pembelajaran tidak selalu dilakukan dengan tatap muka, namun pembelajaran tetap berorintasi pada kegiatan siswa. Kegiatan-kegiatan utama pada pembelajaran berbasis whatsapp group pada kelas IV SD No.2 Mengwitani berupa pemecahan masalah, mengkreasikan konten, menciptakan suatu karya, melakukan hobi, menanggapi dan menjawab siswa dan guru serta hal-hal yang mengasah keterampilan siswa. Kegiatan tersebut jelas berorientasi pada keterampilan siswa. Sesuai dengan Menteri Pendidikan dan Kebudayaan bahwa belajar dari rumah (daring) dapat difokuskan pada pendidikan kecakapan hidup (Dewi, 2020: 20).

Aspek kecakapan hidup meliputi kreativitas. Kreativitas dalam hal ini menurut Bintoro \& Zuliana (2015: 3) membuat kombinasi-kombinasi baru, melihat hubungan-hubungan baru antar unsur, atau hal-hal yang sudah ada sebelumnya. Sehingga dalam hidup diperlukan kretivitas untuk 
memberikan perubahan-perubahan yang dapat meningkatkan kualitas diri, mampu mengikuti perkembangan zaman, dan mampu bersaing dalam segala aspek kehidupan .

Dampak dari pembelajaran daring dengan Whatssapp Group pada prilaku Kreatif Siswa kelas IV SD No.2 Mengwitani yakni siswa menyatakan ide atau tanggapan yang dimilikinya kepada siswa lain. Pemberian ide dilakukan pada saat siswa menyelesaikan masalah terhadap rumusan masalah yang ditetapkan oleh guru. Tujuan dari penyelesaian masalah ini menurut Masfu'ah \& Pratiwi (2018:182) agar siswa mampu menganalisis antar konsep dan mampu memecahkan permasalahan serta membuat keputusan dalam kehidupan sehari-hari. Perilaku keratif lainnya sebagai dampak pembelajaran daring Whatssapp Group yakni siswa bersikap terbuka dengan mendengarkan pendapat dari orang lain. Kegiatan ini tercermin pada siswa yang menaggapi dan menjawab siswa lain. Hal ini terintegrasi dengan pengembangan karakter siswa yakni nilai toleransi. Pelaksanaan nilai toleransi menurut Maunah (2015:94) dilakukan dengan cara menghormati teman yang berbeda pendapat atau paham. Kegiatan ini ternyata bisa dilakukan tanpa melalui tatap muka di dalam kelas. Selanjutnya perilaku kreatif yang dikembangkan yakni siswa menghasilkan ide atau karya yang baru serta melakukan percobaan yang baru. Dampak ini terjadi sebab siswa melakukan kegiatan mengkreasikan suatu konten dan melakukan hobi. Kegiatan menghasilkan ide atau karya yang baru serta melakukan percobaan yang baru dapat meningkatkan motivasi siswa, meningkatan pemecahan masalah, meningkatkan kerja kelompok, dan meningkatkan mengelola sumber (Susanti dalam Suciani, Lasmanawati, Rahmawati, 2018:78).

\section{KESIMPULAN}

Berdasarkan uraian tersebut di atas dapat disimpulkan yaitu sebagai berikut:

1. Dengan menggunakan WhatsApp proses pembelajaran agama Hindu kelas IV di SD No.2 Mengwitani dapat berjalan dengan lancar diaplikasikan dengan cara mengirim gambar, video, berdiskusi, mengirim dokumen berupa word dan masih banyak lagi. Sehingga memudahkan guru dalam sistem pembelajaran daring saat ini.

2. Dalam penggunaan aplikasi WhatsApp di SD No.2 Mengwitani terdapat konten grup chat, yaitu dalam satu grup terdiri beberapa orang, serta mampu dalam jumlah banyak. WhatsApp grup menjadi konten dalam aplikasi WhatsApp yang saat ini sedang popular. Saat ini dengan adanya grup chat memudahkan guru dalam mengirimkan tugas sesuai dengan kelas masingmasing, dan jika ada kendala atau permasalahan akan di bahas langsung dalam Whatsapp grup.

3. Pembelajaran Daring di SD No.2 Mengwitani meskipun tidak selalu dilakukan dengan tatap muka, namun pembelajaran tetap berorintasi pada kegiatan siswa. Kegiatan-kegiatan utama pada pembelajaran berbasis whatsapp group pada kelas IV SD No.2 Mengwitani berupa pemecahan masalah, mengkreasikan konten, menciptakan suatu karya, melakukan hobi, menanggapi dan menjawab siswa dan guru serta hal-hal yang mengasah keterampilan siswa.Kegiatan tersebut berorientasi mengasah keterampilan siswa.

\section{DAFTAR PUSTAKA}

Bintoro, H. S., \& Zuliana, E. 2015. Pembelajaran Realistic Mathematics Education (Rme) Ditinjau Dari Kreativitas Belajar Matematika Siswa Terhadap Prestasi Belajar Matematika Siswa. Refleksi Edukatika, 4(1).

Cetinkaya, L. 2017. The impact of WhatsApp use on success in education process. International Review of Research in Open and Distributed Learning, 18(7).

Dewi, W. A. F. 2020. Dampak Covid-19 terhadap implementasi pembelajaran daring di Sekolah Dasar. Edukatif: Jurnal IImu Pendidikan, 2(1), 55-61. 
Masfuah, S. \& Pratiwi, I.A. 2019. Pentingnya Kemampuan Pemecahan Masalah dan Karakter Bersahabat. Prosiding Seminar Nasional Penguatan Pendidikan Karakter Pada Siswa Dalam Menghadapi Tantangan Global.

Salam, M. 2020. WhatsApp: Presence, Learning Activities, and Learning Outcomes. Jurnal Pendidikan Matematika, 11(2).

Utaminingsih, S., Agustini, F., \& KHB, M. A. 2019. Pengembangan Media Scrap Book Tema 4 Berbagai Pekerjaan Subtema 3 Pekerjaan Orang Tuaku. Jurnal Penelitian dan Pengembangan Pendidikan, 3(2), 64-70.

Xue, S., \& Churchill, D. 2020. Educational affordances of mobile social media for language teaching and learning: a chinese teacher's perspective. Computer Assisted Language Learning, 1-30 